\title{
The economic burden of asthma: direct and indirect costs in Switzerland
}

\author{
T.D. Szucs*, H. Anderhub ${ }^{+}$, M. Rutishauser ${ }^{\ddagger}$
}

The economic burden of asthma: direct and indirect costs in Switzerland. T.D. Szucs, H. Anderhub, M. Rutishauser. (C)ERS Journals Ltd 1999.

ABSTRACT: Asthma mortality increased in Switzerland between 1980 and 1994. This study aimed to assess the economic burden of asthma in this country.

Chart reviews were conducted for the last five patients seen for asthma in physician practices in 1996 and 1997. Direct expenditures and indirect costs for asthma-related morbidity were determined.

A total of 589 patient charts were completely analysed, including 117 children's charts, obtained from 120 office-based physicians. The annual direct medical costs were $C H F 1,778$ and the mean annual indirect costs were $C H F 1,019$ per patient for all patients. The total estimated cost of asthma in Switzerland in 1997 was nearly CHF 1,252 million. Direct medical expenditures approached CHF 762 million, or $61 \%$ of the total. In 1997, the indirect costs for asthma were estimated to have exceeded CHF 490 million. Of these costs CHF 123 million $(25 \%)$ was associated with morbidity and nearly CHF 368 million (75\%) was associated with looking after asthmatic patients who had to be cared for at home.

This study provides evidence that asthma is a major healthcare cost factor in Switzerland, amounting to approximately CHF 1,200 million per year. The data suggest that cost savings can be achieved by improving primary care for asthma in an ambulatory setting.

Eur Respir J 1999; 13: 281-286.

Asthma is a common illness estimated to affect approximately 480,000 people $(7 \%)$ in Switzerland $[1,2]$. Most patients with asthma have mild symptoms, which can easily be controlled with outpatient care. Recent increases in morbidity and mortality associated with this condition $[1,2]$, however, suggest the need to re-examine each aspect of control and prevention. This is especially striking as mortality rates have decreased for most diseases in Switzerland, whereas asthma-related deaths increased by $28 \%$ between 1980 and 1994 [3]. One important component of the morbidity caused by asthma in Switzerland is its economic impact.

The field of economic appraisal has grown tremendously over the last few years as a response to healthcare cost-containment policies [4]. Several types of economic study have been developed to assist in healthcare policy management $[5,6]$. A study of the costs of an illness can provide insight into how healthcare resources addressing a condition are distributed, and can lay the groundwork for further policy decisions that will more effectively channel financial resources toward this disease [7].

\section{Materials and methods}

Physician and patient sample

A total of 2,770 physicians was initially invited to participate in the study by a letter stating the objectives and
*Centre for Pharmacoeconomics, University of Milan, Milan, Italy. ${ }^{+}$Freiestrasse 211, Zürich, Switzerland. ${ }^{\ddagger}$ Children's Hospital, University of Basel, Basel, Switzerland

Correspondence: M. Rutishauser

University Children's Hospital

Römergasse 8

$\mathrm{CH}-4005$ Basel

Switzerland

Fax: 41616856566

Keywords: Asthma

cost of illness

costs

economic evaluation

Received: April 281998

Accepted after revision September 291998

An unrestricted research grant was provided by Merck Sharp \& Dohme-Chibret AG, Glattbrugg, Switzerland. the design of the study. They were asked to provide the number of asthmatic patients being treated in their practice and to indicate whether or not they wanted to participate. Participating physicians (see Appendix) were asked to provide retrospective chart reviews for the last five patients seen for asthma in order to minimize selection bias, i.e. selecting patients with a particular level of disease severity. The review was conducted by advanced medical students directly in the physician's office. Such an approach enabled a coherent and consistent collection of data and offered the possibility of resolving questions on resource utilization directly with the participating physicians. All asthmarelated healthcare utilisation and events were collected, covering a 12-month observation period between September 1, 1996 and August 8, 1997. Moreover, information on the type of asthma treatment was collected by determining whether the patient required long-term drug treatment as opposed to acute treatment for attacks and exacerbations.

\section{Cost estimates}

Asthma-related costs include direct expenditures for medical care and medical costs [8]. In this study, the direct expenditures for medical care included cost and charges (as a proxy for costs) for hospitalization, outpatient services, physicians' services (office visits) and medications. Information on drugs indirectly related to asthma therapy, e.g. treatment for candidiasis and oesophageal reflux, among 
others, were difficult to obtain and were not completely taken into consideration. Indirect costs arising from morbidity and mortality included the value of time lost from work by the patients and by caretakers of patients with asthma, respectively.

\section{Expenditure for medical care}

Hospital care. Expenditures were estimated by multiplying the number of days of hospitalization reported by the costs (including federal subsidies) per inpatient day spent in a general or specialized hospital. Not included were federal subsidies provided to hospitals by the Swiss government. The cost per day amounted to CHF 1,000 . Visits to the emergency department without a subsequent hospitalization were not valued, since the individual services rendered could not be accessed.

Visits to physicians' offices. To estimate expenditure for outpatient care provided in physicians' offices, the number of services rendered in each visit for asthma was multiplied by the average charges for individual services (including home visits) in 1995. This average fee was calculated as the mean from seven different regions (Basel-Stadt, Baselland, Bern, Lucerne, St Gallen, Neuchatel and Vaud). The most frequent unit charges are listed in table 1. Data on community nursing were not collected specifically, because these do not play a major role in asthma management in Switzerland.

Other costs. Indirect medical costs, e.g. ambulance services, were not valued, because these services are charged directly to the corresponding sickness funds or insurance companies. Patient travel costs, being mainly cash expenditures, were not determined since they could not be extracted from the medical records.

Medications. Data on antiasthma medications were taken directly from the medical records (physicians are allowed to sell medications directly to the patients in some cantons, e.g. St Gallen and Baselland). The aver-

Table 1. - Unit cost of resources

\begin{tabular}{lc}
\hline Resources & Cost CHF \\
\hline Lung function & 100 \\
Spirometry & 50 \\
Chest radiography & 70 \\
Blood gas analysis & 80 \\
Arterial puncture & 20 \\
Aerosol inhalation & 100 \\
Methacholine provocation test & 120 \\
Skin-prick test & 30 \\
Physiotherapy (18 session) & 360 \\
Immunoglobulin & 35 \\
RAST & 90 \\
Theophylline plasma levels & 40 \\
Erythrocyte sedimentation rate & 6 \\
Haemoglobin & 7 \\
Differential blood count & 23 \\
Physician visit & 20 \\
Express consultation & 30 \\
Telephone consultation & 10 \\
\hline RAST: Radiallegosorbent test
\end{tabular}

RAST: Radioallergosorbent test. age annual costs of medication were estimated by multiplying the average public prescription price for each drug ( $\beta$-agonists, theophyllines, corticosteroids, cromolyn) by the number of packs prescribed per year. Public prescription prices were obtained from the 1997 Swiss Drug Compendium (Arzneimittelkompendium) [9].

\section{Indirect costs}

Loss of work. Costs for asthma-related loss of work (including the period of hospitalization) were calculated for people currently employed using the human capital approach. The costs were derived from the number of asthma-related days of work lost multiplied by the average daily earnings (CHF 385). This is the official figure reported by the Swiss Office of Statistics [10]. Data on the number of days for which a caretaker had to stay away from work to look after an asthmatic patient were also collected. The costs were determined by multiplying the number of days off work with the average daily income (before tax) on the basis of official employment statistics in Switzerland (CHF 385).

Loss of school days. The number of days away from school was calculated. However, no economic costs were attributed.

\section{Clinical data}

Although resource utilization was the primary interest of this study, selected clinical data were also collected which were felt to be important for further analyses. Such parameters included the number of attacks, number of exacerbations, length of attacks/exacerbations, last measured forced expiratory volume in one second (FEV1) values and concomitant illnesses related to asthma.

\section{Results}

A total of 384 physicians participated and provided data on the number of asthmatic patients they regularly treat in their practice. On average, these physicians saw 23 (general practitioners) and 53 (paediatricians) asthmatic patients per year. The final sample was taken from 120 office-based physicians from six different regions (Basel 7 (6\%), Baselland $10(8 \%)$, Berne $39(33 \%)$, Lucerne 12 (10\%), St Gallen 26 (22\%), Neuchatel $10(8 \%)$ and Vaud $16(13 \%))$ who were willing to participate in the study and offered access to their medical charts. The main reason for not participating in the study was due to the reluctance of several physicians to give access to their medical records. It was, therefore unlikely, that only physicians interested in asthma were included in the study.

These regions include 2,944 million inhabitants (42\% of the Swiss population). Physicians were either general practitioners $(47 \%)$, internists $(25 \%)$, lung specialists $(11 \%)$ or paediatricians (11\%). This sample represents $5 \%$ of all office-based practising physicians in Switzerland.

\section{Patient characteristics}

A total of 589 patient charts were analysed, including 117 children. The demographic data of these patients are 
Table 2. - Patient demographics

\begin{tabular}{lccc}
\hline Variable & All patients & Children & Adults \\
\hline $\mathrm{n}$ & 589 & 117 & 472 \\
Age yrs & $43.9 \pm 25.2$ & $9.8 \pm 2.41$ & $52.4 \pm 20.8$ \\
Height cm & $161.1 \pm 15.9$ & $139.5 \pm 15.3$ & $167.3 \pm 9.3$ \\
Weight kg & $65.75 \pm 21.3$ & $37.8 \pm 20.8$ & $72 \pm 15.7$ \\
Asthma diagnosed & $10.62 \pm 13.7$ & $4.56 \pm 3.5$ & $12.18 \pm 14.9$ \\
$\quad$ since yrs & & & \\
Type of asthma & & & \\
$\quad$ treatment* & & 50 & 73 \\
$\quad$ Long-term & & \\
$\quad$ As-needed $\%$ & 69 & 49 & 24 \\
\hline
\end{tabular}

Data are mean \pm SD. *: Figures do not add up to $100 \%$; the remainder indicates unknown treatment status; ${ }^{\dagger}$ : continuous treatment between attacks/exacerbations; ${ }^{*}$ treatment only during attacks/exacerbations.

listed in table 2. Although disease severity was not specifically collected for the purpose of the study, the annual rate of attacks and exacerbations was analysed. In the patients studied, $34 \%$ of adults and $32 \%$ of the children experienced attacks/exacerbations during the observation period. The mean number of attacks/exacerbations in these patients was approximately $1.8 \cdot \mathrm{yr}^{-1}$ in these $162 \mathrm{ad}-$ ults and 38 children. About one-quarter of adult patients and half of the children required treatment solely for the management of acute attacks and/or exacerbations, leaving the remainder on continuous long-term treatment.

\section{Resource utilization}

Direct medical costs. The annual direct medical costs are shown in table 3 . In absolute terms, drug costs were the largest cost factor in children $(41.3 \%$ of total direct costs) whilst being lower in adults. Furthermore, hospital care was a major cost factor in adult patients and accounted for $46.5 \%$ of total direct costs.

Indirect costs. Indirect costs were determined on the basis of asthma-specific labour-force participation rates (table 4). Hence, the mean of the annual indirect costs per patient was CHF 1,019 for all patients (CHF 30 in children and CHF 1,264 in adults). The largest proportion of indirect costs was attributed to productivity losses from the patient caregivers, even for adults, and not from the patients themselves. For example, the costs for caregivers for adults were CHF 946 per year, whereas the indirect costs incurred by adult patients were CHF 318 per year. Indirect costs in children were CHF 30 per patient, based completely on productivity losses by the caregivers

Table 3. - Mean direct medical costs per year per patient in Swiss francs

\begin{tabular}{lccc}
\hline Cost category & All patients & Children & Adults \\
\hline $\mathrm{n}$ & 589 & 117 & 472 \\
Outpatient care & 196 & 139 & 210 \\
Medication & 653 & 340 & 731 \\
Inpatient care & 722 & 299 & 826 \\
Referrals & 12 & 15 & 11 \\
Total & 1583 & 793 & 1778 \\
\hline
\end{tabular}

Table 4. - Labour-force participation rate of patients with asthma in Switzerland

\begin{tabular}{lrcr}
\hline Status & $\begin{array}{c}\text { All } \\
\text { patients }\end{array}$ & $\begin{array}{c}\text { Children } \\
(6-14 \text { yrs })\end{array}$ & $\begin{array}{c}\text { Adults } \\
(\geq 15 \text { yrs })\end{array}$ \\
\hline Full-time & 27 & 0 & 34 \\
Part-time & 3 & 0 & 3 \\
Self-employed & 3 & 0 & 4 \\
Not employed & 8 & 0 & 11 \\
Jobless & 2 & 0 & 2 \\
Pensioner & 25 & 0 & 31 \\
Disability pensioner & 4 & 1 & 4 \\
Scholar & 23 & 90 & 6 \\
Student & 2 & 0 & 2 \\
No data & 4 & 9 & 3 \\
Total & 100 & 100 & 100 \\
\hline
\end{tabular}

Data are shown as percentages.

Total costs (direct plus indirect costs). The mean annual direct and indirect costs amounted to $\mathrm{CHF}$ 2,602 per patient in the overall study group. Costs were higher in adult groups (CHF 3,042) than in children (CHF 823). The corresponding cost structure of asthmatic patients is shown in figure 1 .

In order to determine the economic significance of attacks and exacerbations on total treatment costs, the number of attacks/exacerbations had to be determined (table 5). On average, 0.63 attacks/exacerbations were observed per patient, 0.60 per patient among children and 0.63 among adults. In $41 \%$ of children, a visit to a physician was required and in $3.4 \%$ hospitalization. The corresponding percentages in adults were $55.7 \%$ and $31 \%$, respectively. The difference between children and adults was statistically significant with respect to physician visits $(\mathrm{p}<0.01,95 \%$ confidence interval $(\mathrm{CI})-0.25-$ -0.05). Total costs in patients with attacks were CHF 4,227 , whereas annual treatment costs in patients without attacks in the observation period were CHF 1,770 (fig. 2). There was a striking trend towards higher treatment costs in patients treated with steroids (adults: CHF 3,307; children: 945) than in those not receiving any steroids

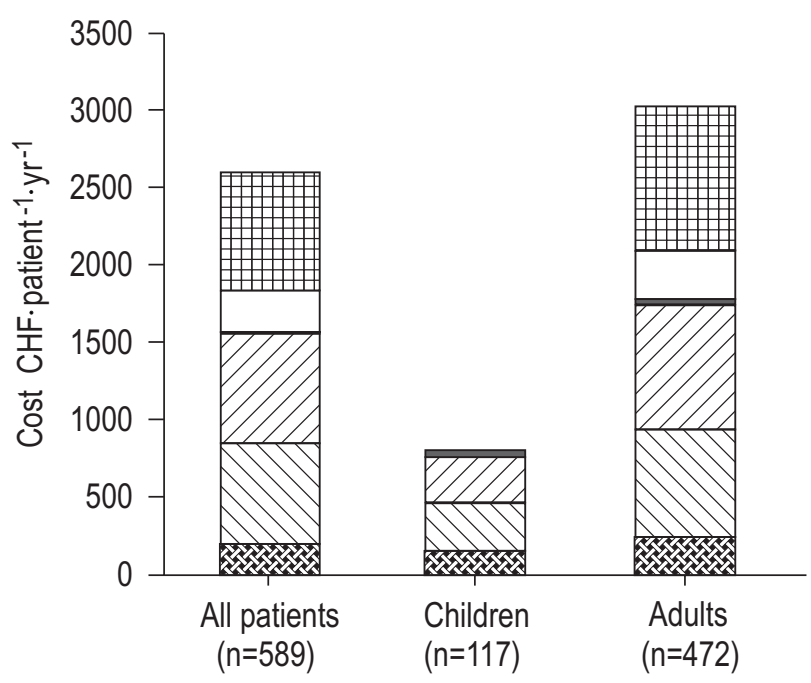

Fig. 1. - Total annual cost of patients with asthma in Switzerland. 曲: indirect costs (caregivers); $\square$ : indirect costs (patients); $\mathbf{\square}$ : referrals; $\mathbb{Z}$ :

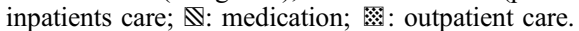


Table 5. - Physician visits, specialist referrals, diagnostic measures and hospitalization

\begin{tabular}{|c|c|c|c|}
\hline Status & All patients & Children (6-14 yrs) & Adults $(\geq 15$ yrs $)$ \\
\hline $\mathrm{n}$ & 589 & 117 & 472 \\
\hline \multicolumn{4}{|l|}{ Physician visits } \\
\hline Total & 3080 & 446 & 2634 \\
\hline Per patient & 5.2 & 3.81 & 5.6 \\
\hline \multicolumn{4}{|l|}{ Referrals } \\
\hline Total & 140 & 36 & 104 \\
\hline Per patient & 0.24 & 0.31 & 0.22 \\
\hline \multicolumn{4}{|l|}{ Hospitalizations } \\
\hline Total & 50 & 8 & 42 \\
\hline Per patient & 0.08 & 0.07 & 0.09 \\
\hline Total patients & 43 & 8 & 35 \\
\hline Hospital days/patient & 0.72 & 0.3 & 0.83 \\
\hline Average length of stay per hospitalized patients days & 9.86 & 4.39 & 11.2 \\
\hline Average length of hospitalization days & 8.48 & 4.39 & 9.32 \\
\hline Diagnostics & 0.18 & 0.18 & 0.18 \\
\hline \multicolumn{4}{|l|}{ Lung function per patient } \\
\hline Spirometry & 0.52 & 0.46 & 0.53 \\
\hline Chest radiography & 0.18 & 0.07 & 0.21 \\
\hline \multicolumn{4}{|l|}{ Days off work } \\
\hline Total patients with days off work & 62 & 9 & 53 \\
\hline In $\%$ of all patients & 10.5 & 7.7 & 11.2 \\
\hline Days off work per patient & & 0 & 28 \\
\hline Total caregivers with days off work & 11 & 8 & 3 \\
\hline In $\%$ of all patients & 1.9 & 6.8 & 0.6 \\
\hline Days off work per patient caregiver & 10 & 2 & 25 \\
\hline
\end{tabular}

during the observation period (adults: CHF 1,577; children: CHF 385). This difference was due not only to higher medication costs but also to all other cost categories, suggesting that these patients were also more severely ill than nonsteroid users.

\section{Epidemiology of asthma in Switzerland}

Epidemiological studies in Switzerland suggest a prevalence of asthma of $6.7 \%$ in adults [11] and $7.4 \%$ in children [12]. Thus, it can be estimated that in Switzerland about 86,000 children and 395,000 adults suffer from asthma.

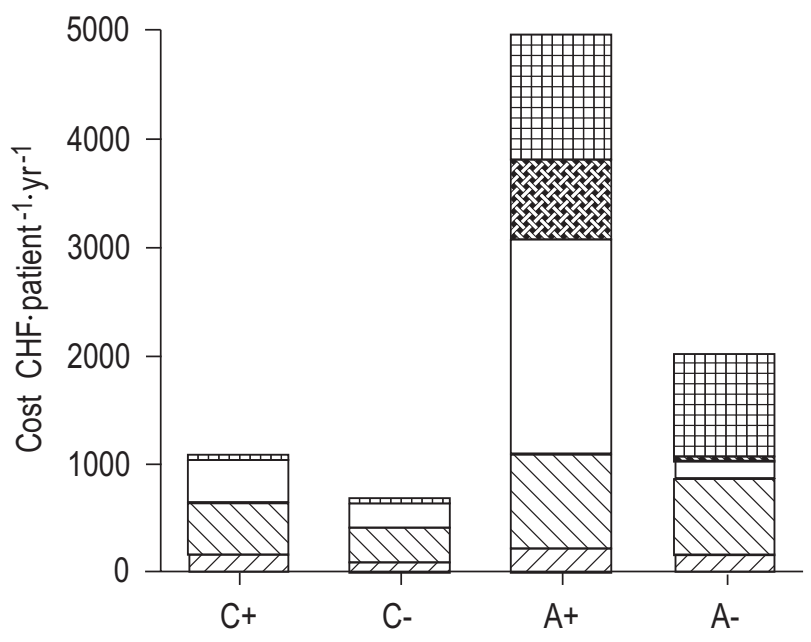

Fig. 2. - Comparison of annual costs in patients with and without attacks and exacerbations. $\mathrm{C}+$ : children with attacks $(\mathrm{n}=38)$; $\mathrm{C}$-: children without attacks $(n=79)$; A+: adults with attacks $(n=162)$; A-: adults without attacks $(\mathrm{n}=309)$. 曲: productivity loss (caregivers); : productivity

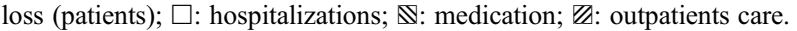

\section{Total healthcare expenditure for asthma in Switzerland}

Drug therapy is the principal treatment for asthma, with total estimated prescriptions exceeding 4.6 million. This study suggests an average of 41,595 hospitalizations annually for asthma alone, with $15 \%$ involving people $\leq 14$ yrs of age. The average length of a hospital stay was 9.2 days in adults and 4.3 days in children. Hospital expenditures were estimated at CHF 348 million, with $7 \%$ of this total being spent on children, i.e. those younger $\leq 14$ yrs of age.

In the group of children, asthma was responsible for a loss of $>172,494$ days of caretakers' time from work. Asthma in Switzerland accounts for a total loss of nearly 11 million work days among patients $\geq 15$ yrs of age as well as 9.8 million work days for caretakers.

The total estimated cost of asthma in Switzerland in 1997 was close to CHF 1,252 million. Direct medical expenditures approached CHF 762 million, or $61 \%$ of the total. The largest category of direct medical expenditure was that of hospitalizations (CHF 348 million), with drug prescriptions being the second largest category (CHF 314 million). Physicians charges accounted for CHF 94 million, or almost $6 \%$ of the direct expenditures.

In 1997, the indirect costs for asthma were estimated to have exceeded CHF 490 million. Of these costs CHF 123 million $(25 \%)$ were associated with morbidity, whereas nearly CHF 368 million (75\%) were associated with the home care of asthmatic patients.

\section{Discussion}

Healthcare systems are meant primarily to reduce morbidity and premature death. Studies of the cost of a given illness can provide insights into the pattern and 
categories of spending for that particular disease and clear the path for the necessary modifications to reduce therapy costs. Expenditures for asthma medications in Switzerland approach an impressive CHF 314 million annually. Today, drug therapy for asthma consists mainly of topical steroids, long- and short-acting $\beta$-agonists and has moved away from cheaper medication, e.g. theophyllines. More expensive prophylactic medications such as cromolyn and ketotifen have been replaced widely, as well as older medication such as antihistamines. Topical steroids and longacting b-agonists are expensive drugs and the observed trend is accompanied by a rise in the costs of asthma medication. The overall costs of asthma treatment, however, are expected to decrease, as better and more effective drugs help to reduce asthma morbidity. In this case, reimbursement systems should be able to accommodate easily the increased expenditure for asthma pharmacotherapy.

Socioeconomic studies also have their limitations and caution must be exercised in their interpretation. The cost per unit of service as well as the value of resource used in the treatment of asthma itself are, at times, hard to quantify with sufficient accuracy. Calculating the cost of an illness requires information on all major direct expenditures as well as indirect costs. The present data may represent a conservative estimate of the overall costs, because no data were collected on community nursing services or the costs for visits to an emergency department without subsequent hospitalization. To the authors' knowledge, no large-scale study to analyse medical charts has yet been performed in Switzerland.

The results of this study extend the findings of previous research in this area. Other cost-of-illness studies have been performed in several European and non-European countries [13-18]; however, a direct comparison is difficult. A comparison may be feasible with Germany, a country with a similar socioeconomic environment and approach to healthcare delivery [19]. Here, the estimates of direct medical expenditure and indirect costs were derived from the official health statistics of 1992. By adding direct and indirect costs, the total amounts to approximately 5.13 billion DEM for a population of 80.3 million inhabitants. Of this, $61.5 \%$ is direct costs, consisting of outpatient care, drugs, hospital treatment, rehabilitation and compensation for occupational asthma as well as sickness benefits, and $38.5 \%$ is indirect costs, caused by payments for days off work, premature retirement and premature death due to asthma.

A similar retrospective study was performed in Germany [20]. Using standardized questionnaires, data were acquired from 216 patients and assigned to subgroups in accordance with the degree of severity of asthma. The patients were treated in the offices of 23 general practitioners and internists, selected at random from a list of all relevant practices in Germany. The use of resources, i.e. all diagnostic and therapeutic measures, were recorded retrospectively for a period of $1 \mathrm{yr}$. In addition to direct costs, indirect costs, e.g. productivity losses due to illness-related absence from work, were estimated. The annual costs of treating adult asthmatics were calculated, ranging DEM 3,330-DEM 12,016. With progression of the disease, direct costs due to hospitalization in particular, as well as indirect costs, rose in a disproportionate manner. For children, the annual direct costs of asthma treatment were between DEM 2,950 and DEM 4,811.
Improving asthma care means focusing on the providers of care. Nearly $75 \%$ of ambulatory visits for asthma involve physicians from the three primary care specialities, general practitioners $(43.1 \%)$, paediatricians $(11.1 \%)$ and internists (20-22\%) [21]. Improving asthma care with the goal of reducing overall costs means enlisting the participation of these providers and improving their models of care rather than focusing on asthma specialists alone.

This study allows an estimation of the potential economic impact of managing asthma with effective intervention programmes. The impressive figure of total costs for asthma, as a percentage of Swiss total healthcare expenditure, becomes more transparent when categorizing costs according to inpatients and outpatients. The statistical report of the Swiss Association of Hospitals has shown the average length of stay for asthmatic patients to be 13 days [22]. The largest single category of direct costs in the present study was due to hospitalization. Studies have suggested that relatively inexpensive, primary care-based intervention strategies, e.g. health education of patients and doctors, regular follow-up of patients in doctors' offices and by paramedical personnel as well as structured home care, considerably help to reduce the number of hospitalizations.

The potential of cost savings achieved by shifting from extremely expensive hospital care to far less expensive ambulatory care becomes readily apparent from these analyses. Therefore, if the costs of asthma treatment are to be reduced and with regard to any future efforts in directing health policy towards the improvement in asthma care, emphasis should be placed on improving the effectiveness of primary care for asthma in an ambulatory setting. There seems to be no doubt that significant savings in total healthcare expenditure can easily be achieved by a shift towards newer, more innovative, albeit more expensive, medications by helping to reduce the severity of asthmarelated morbidity. As an additional bonus, the quality of life in these patients is improved considerably. More detailed pharmacoeconomic considerations of new therapeutic modalities that go beyond a simple cost-of-unit thinking, which include quality-of-life assessments, will clearly be needed to demonstrate the value of future approaches in managing asthma and asthma-related disorders.

Acknowledgements. The authors would like to thank L. Borer, Merck Sharp \& Dohme-Chibret AG, Glattbrugg, Switzerland. Special thanks goes to all participating physicians, to $\mathrm{M}$. Prince for logistical support and U. Bossi for her assistance in styling the manuscript.

\section{Appendix}

The following physicians participated in the study: U. Aebi, Biel; P. Affolter, Basel; W. Ammann, Neuchâtel; M. Augstburger, St Gallen; E. Bachmann, Bremgarten; W. Bachmeier, Langnau; A. Bächler, St Gallen; Y. Barbier, Lausanne; M. Bieler, St Gallen; M. Bigler, Rorschach; A. Bornet, Château d'Oex; R. Bourgeois, Chardonne; C. Brügger, Bazenheid; C. Bühler, Liebefeld; U. Bürki, Thun; E. Büsser, Luzern; S. Th. Christen, Hasle-Rüeggsau; R. Christen, Thun; M. Corneo, Richen; R. Denoth, Rorschach; J-B. Drapel, Renens; H-U. Dubach, Langenthal; D. Dürr, 
Heimberg; A. Durrer, Bern; H-J. Eglin, Riehen; B. Estermann, Malters; U. Fahrni, Thun; D. Flach, Biel; J. Fritschi, Obernau; J.J. Fritschi, Pfeffingen; B. Frühauf, Walenstadt; R. Furer, Münsingen; A. Gehl, Buchs; A. Geiger, Saint-Prex; M. Giordano, Le Locle, F. Glassey-Perrenoud, La-Chaux-de-Fonds; M.P. Gnädinger, Steinach; M. Grossenbacher, Ringgenberg; R. Gubser, Neuchâtel; R. Härri, Boltigen; R. Hauser, Schönbühl-Urtenen; M. Hausmann, Pratteln; H. Hochreutener, Interlaken; P. Hutter, Niederuzwil; M. Kägi, Bern; B.J. Keist, Ebnal-Kappel; G. Keller, Kronbühl; P. Kindler, Arlesheim; G. Klein, Wauwil; C. Knoll, Biel; A. Kramis, Emmenbrücke; J-P. Kulling, Gland; B. Kuster, Luzern; C. Laperrouza, St-Aubin NE; B. Laubscher, Neuchâtel; J-D. Lavanchy, Yvonand; S. Lehmann, Reigoldswil; B. Liechti, Bern; L. Litschgi, Basel; A. Luder, Interaken; C. Mützener, Stettlen; A. Marti, Brügg; P. Meier, Sissach; J-C. Meuwly, Yverdon-les-Bains; P. Mo Costabella, Lausanne; A. Molnar, Prilly; S. Mosimann, Lützelfüh; A. Mourad, Vevey; C. Mullis, St Gallen; R. Naegeli, Rüthi; P-A. Nicod, Froideville; G. NicoletChatelain, Nyon; B. Ninck, Zell; W. Oesch, Gommiswald; A. Packy, St Gallen; J-M. Perrin, Münsingen; C. Pletscher, Murg; B. Portmann, Ruswil; F. Racine, Bevaix; E. Riesen, Ziefen; M. Röthlisberger, Bützberg; C. Röthlisberger, Grossaffoltern; J. Rohrer, Bern; F. Rohrer, Lausen; L. Rützler, Altstätten; C. Schibler, St Gallen; K. Schiess, Mosnang; R. Schlaepfer, La-Chaux-de-Fonds; H. Schmid, St Gallen; I. Schmid, Basel; U. Schneeberger, Niederönz; H. Schön, Hochdorf; R. Schück, Heerbrugg; G-C. Serena, Basel; B. Siegrist, Bern; E. Singeisen, Rohrbach; P. Sladovnik, Reussbühl; C. Solèr-Bischof, Will; C. Somadin, St Gallen; B. Spillmann, Basel; Y. Stocker, Will; M. Strupler, Grindelwald; R. Stucki, Lutry; H. Suter, Lyss; C. Teelmann, Allschwil; E. Thürig, Nebikon; F. Verdon, Neuchâtel; J.A. Vögeli, Biel; A. von Graffenried, Biglen; H. Wacker, Allschwil; J. Wacker, La Chaux-de-Fonds; P. Wälchli, Meiringen; R. Wälli, Jona; G. Wagner, Lausanne; J. Weber, Bottmingen; A. Weiersmüller, Bern; M. Werder, Luzern; P. Widmer, Crans/Céligny; Y. Zgraggen, Thörishaus; A.Z. Schmid, Münsingen.

\section{References}

1. Sly RM. Mortality from asthma, 1979-1984. J Allergy Clin Immunol 1988; 82: 705-717.

2. Gergen PJ, Weiss KB. Changing patterns of asthma hospitalisation among children: 1979 to 1987. JAMA 1990; 264: 1688-1692.

3. Mortality statistics. Bern, Swiss Federal Office for Statistics, 1997.

4. Elixhauser A, ed. Healthcare cost-benefit and cost- effectiveness analysis (CBA/CEA). From 1979 to 1990: a bibliography. Med Care 1993; 3: Suppl. 1-149.

5. Szucs TD, Schramm W. Die sozioökonomische Evaluation. Einführung in die Methodologie. Hämostaseologie 1994; 14: 84-89.

6. Drummond MF, Stoddard GL, Torrance GW. Methods for the economic evaluation of health care programmes. Oxford, Oxford Medical Publications, 1987.

7. Hodgson TA. Costs of illness in cost-effectiveness analysis: a review of the methodology. Pharmaco Economics 1994; 5: 536-552.

8. Rice DP, Hodgson TA, Kopstein AN. The economic costs of illness: a replication and update. Health Care Financ Rev 1985; 7: 61-80.

9. Arzneimittelkompendium der Schweiz. Basel, Documed, 1997.

10. Swiss Statistical Yearbook. Zürich, Neue Zürcher Zeitung, 1997.

11. Leuenberger P. Air pollution in Switzerland and respiratory disease in adults. Results of the cross-sectional part of the Salpadia study. [German]. Schweiz Rundsch Med Prax 1995; 84: 1096-1100.

12. Robertson CF, Bishop J, Sennhauser FH, Mallol J. International comparison of asthma prevalence in children: Australia, Switzerland, Chile. Pediatr Pulmonol 1993; 16: 219-225.

13. Mellis CM, Peat JK, Bauman AE, Woolcock AJ. The cost of asthma in New South Wales. Med J Aust 1991; 155: 522-528.

14. National Asthma Campaign. Report on the cost of asthma in Australia, 1992, 14-33.

15. Teeling-Smith G. Asthma. London, Office of Health Economics, 1990.

16. Thompson S. On the social costs of asthma. Eur J Respir Dis 1984; 65: 185-191.

17. Jacobson L, Lindgren B. Astma. De samhällsekonomiska kostnaderna. Studier i hälsöckonomia. 8 Lund, Lund Universitet, 1995

18. Weiss KB, Gergen PJ, Hodgson TA. An economic evaluation of asthma in the United States. $N$ Engl J Med 1992; 326: 862-866.

19. Nowak D, Volmer T, Wettengel R. Asthma bronchiale eine Krankheitskostenanalyse. Pneumologie 1996; 50: 364-371.

20. Graf von der Schulenburg JM, Greiner W, Molitor S, Kielhorn A. Cost of asthma therapy in relation to severity. [Kosten der Asthmatherapie nach Schweregrad. Eine cempirische Untersuchung]. Med Klin 1996; 91: 670676.

21. International Medical Statistics. Verschreibungsindex Pharma, Switzerland, 1998.

22. Spitalstatistik [Swiss hospital statistics], H+, Aarau, 1997. 